\title{
Vulnerability Analysis of Power Distribution Systems for Cost-Effective Resource Allocation
}

\author{
Carl Johan Wallnerström, Graduate Student Member, IEEE, and Patrik Hilber, Member, IEEE
}

\begin{abstract}
This paper proposes a method to allocate resources in power distribution planning and also introduces a new reliability index category, $R_{T}$, flexibility to adjust to different laws or distribution system operator (DSO) policies of long outages. Possible legal consequences for distribution system operators are first identified and studied. A vulnerability-analysis method is introduced, including a statistical validation. The overall idea is to identify and evaluate possible states of power distribution systems using quantitative reliability analyses. Results should thus indicate how available resources (both human recourses and equipment) could be better utilized, e.g., in maintenance and holiday scheduling and in evaluating whether additional security should be deployed for certain forecasted weather conditions.

To evaluate the method, an application study has been performed based on hourly weather measurements and about 65000 detailed failure reports over eight years for two distribution systems in Sweden. Months, weekdays, and hours have been compared and the vulnerability of several weather phenomena in these areas has been evaluated. Of the weather phenomena studied, only heavy snowfall and strong winds, especially in combination, significantly affect the reliability. Temperature (frost), rain, and snow depth have a relatively low or no impact.
\end{abstract}

Index Terms-Management decision-making, power distribution, reliability, risk analysis, weather forecasting.

\section{INTRODUCTION}

$\mathbf{O}$ UR society has become more dependent on reliable distribution of electricity, and the demand for cost efficiency has increased since new incentives have appeared [1]. There has to be a balance between the aims of high reliability and cost effectiveness. An established method for managing this balance is risk analysis [2]. Risk is often defined as a function of probability and consequence [3]. Evaluating the impacts of outages and the benefits of risk reducing investments are thus valuable. Vulnerability is related to risk, but is a more relative concept, often used in comparative studies of different infrastructure designs or states. Moreover, the vulnerability concept is widely used in other, significant different contexts than analyzing power systems, for example in environmental- [4] and computer security [5] research. The latter is an example of analyses of targeted attacks that indirectly can affect power systems. Vulnerability does not have any commonly accepted definition [6]. A

Manuscript received October 15, 2010; revised February 11, 2011 and May 13, 2011; accepted July 19, 2011. Date of publication September 22, 2011; date of current version January 20, 2012. This work was supported in part by Elforsk, the Swedish National Safety Board, FIE, and EKC2. Paper no. TPWRS-008252010.

The authors are with the School of Electrical Engineering, KTH (Royal Institute of Technology), Stockholm, Sweden (e-mail: cjw@kth.se).

Color versions of one or more of the figures in this paper are available online at http://ieeexplore.iee.org.

Digital Object Identifier 10.1109/TPWRS.2011.2165226 definition of system vulnerability suitable to use in this paper is provided in [7]: "the system's inadequate ability to withstand an unwanted situation, limit the consequences, and recover and stabilize after the occurrence of the situation".

Quantitative methods using reliability indices for cost-effective asset management in power distribution is not a new concept [8], [9]. Furthermore, reliability models which divide power systems into two or three weather states have been proposed [10]. For example, [11] describes a model dividing power distribution systems into the states: "normal weather", "adverse weather", and "major adverse weather". Weather conditions and vulnerability differ considerably between regions, but wind, lightning, and icing/snow are often identified as the most critical conditions [12]. Vulnerability analysis of power systems using reliability and risk-based methods have earlier been proposed, but these methods often focus on a higher system/voltage level [13]. The impact on distribution system reliability indices from single storms have earlier been analyzed in e.g., [14]. This paper proposes a vulnerability analysis method dividing the system into several system states, not limited to weather-related states. Furthermore, a proposal of how to consider long outage compensation models are provided in this paper since traditional reliability indices are related to average reliability.

The vulnerability analysis is performed by comparing the results of risk analyses from each state using quantitative reliability indices. Possible legal consequences for distribution system operators (DSOs), i.e., companies with a regional concession, are presented, exemplified by Sweden and the U.K. A vulnerability model is suggested and evaluated in a case study on two Swedish power distribution systems. The aim of the method is to support cost effective resource allocation in power distribution systems, including both human and economical recourses and equipment. The results from the method could be used to produce maintenance and investment plans, evaluate whether additional preparedness should be deployed based on particular weather forecasts, assess how much security is justified during inconvenient hours and holidays, and identify unacceptable risks.

\section{IMPACT INVENTORY}

\section{A. International Tendencies Towards Increased Impacts}

From the perspective of the DSOs, there are costs for operation and maintenance to balance against the requirements of system reliability and stakeholder profits. In a perfect market environment, a balance would be reached when customers select the DSO with the best price for the required customer value. However, the infrastructure is a natural monopoly. The authorities have therefore taken the task of judge whether the tariffs 
are reasonable. The international tendency is towards more performance-based regulations [15] and several countries, such as the U.K., have introduced laws on customer compensation for long outages in addition. These tendencies motivate more comprehensive and detailed analysis methods applied to power distribution systems.

\section{B. Introduction to Current Swedish Legislation}

In Sweden, the electricity market was de-regulated in 1996 and for distribution tariffs a performance-based regulation was introduced in 2003 [16]. This regulation was however strongly criticized by stakeholders, and in 2009 , the regulator decided to abandon the old model. Sweden will, forced by an EU-law, implement an ex-ante regulation from 2012. Ex-ante is when tariffs are judged before they finally are settled and applied. Furthermore, a law introduced in 2006 stipulates that every DSO has to report annually the result of a risk- and vulnerability analysis with respect to reliability. The DSO is relatively free to choose analysis method, i.e., this demand is neither connected to IEEE nor IEC standards. Additional legalization was introduced for long-term outages from 2006 and a functional requirement of $24 \mathrm{~h}$ is applied from 2011, i.e., outages $\geq 24 \mathrm{~h}$ are not tolerated. Hence, $12 / 24 \mathrm{~h}$ are important limits for Swedish DSOs to consider.

\section{Consequences for Swedish DSOs}

The type of legislation introduced in Section II-B has a significant impact on possible consequences for DSOs. Incidents and their associated consequences for Swedish DSOs are listed in this section.

Categories included in this study:

- Short outages $(0.05-12 \mathrm{~h})$ : The upcoming tariff regulation will be based on reported SAIDI and SAIFI (see Section III-C). The possible consequence for the DSO is decreased income limit, i.e., all customers collectively obtain revised tariff levels. To avoid "double penalization", outages from other categories are excluded. If customers are given sufficient notice of outages, the economic impact will be lower.

- Long outages ( $\geq 12 \mathrm{~h}$ ): Table I summarizes the model for determining customer outage compensation to affected customers.

Categories not included in this study:

- Incidents that did not affect customers.

- Administrative deficiencies and voltage quality: Customer services could, for example, be shorthanded as a consequence of major disturbance. These aspects will probably be integrated in upcoming regulation, but not in the first version applicable from 2011.

- Very short outages $(<0.05 \mathrm{~h})$ : These have traditionally not been included in regulations and statistics, but will be included as a separate category.

- Violating environmental or safety laws: Neither of these fit within the analysis, although very serious.

In addition to the regulatory penalties, there are more uncertain consequences such as damage to the trademark.
TABLE I

CONSEQUENCES OF OUTAGES $>12 \mathrm{~h}$

\begin{tabular}{l|c|c}
\hline \hline \multicolumn{1}{c|}{$\begin{array}{c}\text { Length of the } \\
\text { outage }\end{array}$} & $\begin{array}{c}\text { Compensation to } \\
\text { customer }\end{array}$ & $\begin{array}{c}\text { Minimum } \\
\text { compensation }\end{array}$ \\
\hline $12-24$ hours & $12.5 \%$ of $\alpha$ & $2 \%$ of $\beta$ \\
$24-48$ hours & \\
$\begin{array}{l}\text { Following } 24 \text { hour } \\
\text { periods }\end{array}$ & $+25 \%$ of $\alpha$ & $4 \%$ of $\beta$ \\
& $+25 \%$ of $\alpha$ & $+2 \%$ of $\beta$ \\
Max $^{2}$ & $\vdots$ & - \\
\hline
\end{tabular}

$\alpha=$ Individual customer's annual network tariff; this value depends on both the main fuse (power allowed) and annual energy consumption. $\beta=$ Yearly set base amount (42 400 SEK $2010, \sim 4700 €, \sim 6100 \$)$ )

${ }^{1}$ Is always set to even 100 SEK values, rounded up $\rightarrow 2 \% \beta$ is rounded up to 900 SEK $(\sim 100 €, \sim 140 \$)$

${ }^{2}$ Additional consequences are likely, since $>24$ hours outages not are tolerated by the law from 2011

Another aspect is that negative public opinion can prompt politicians and authorities to impose tougher rules.

\section{VULNERABILITY ANALYSIS MethoD}

\section{A. Method Overview}

1) Determine the accuracy and extent of the analysis.

2) Identify system states (Section III-B).

3) Calculate risk indices for each state (Section III-C-E).

4) Perform a statistical validation (Section III-F).

5) Use the result for cost-effective resource allocation in the investment and maintenance plans (example presented in Section V).

\section{B. Categories of System States}

From the case studies, three categories of system states have been identified as important to study separately:

- Time states (see Section IV-C)

- Weather states (see Section IV-D)

- Reduced-system-performance states, for example when a spare transformer is set aside for maintenance.

For systems in other environments, different categories might need to be defined.

\section{Introduction of a New Risk Index Category}

A new reliability index category, $R_{T}$, is introduced; see (1). The category allows flexibility of design of indices, to adjust to different laws (see, e.g., Section II-C) or DSO policies of long outages. $R_{T}$ is the average number of outages above $T$ hours during one year per 1000 customers (the last motivated to avoid values $\ll 1)$ :

$$
R_{T}=\frac{1000 \sum_{i}\left(\lambda_{\geq T, i} N_{i}\right)}{\sum_{i} N_{i}}[\text { int./year, } 1000 \text { cust.]. }
$$

$\lambda_{\geq T, i}$ is the sum of customer outages/year in $L P_{i}$ caused by outages $\geq T$ hours and $N_{i}$ is the number of customers in $L P_{i}$. The Swedish customer compensation does not take customer category or weather condition into consideration, while in the 
U.K., the customers are separated in two types (domestic and non-domestic) and different compensation levels are used for different weather conditions. Examples of $R_{T}$ related with costs are provided in Section III-E.

In Sweden 12 and $24 \mathrm{~h}$ are most important, i.e., $\mathrm{R}_{12}$ and $\mathrm{R}_{24}$, while $18 \mathrm{~h}$, i.e., $\mathrm{R}_{18}$, is the limit of the first compensation level in the U.K. If an outage interval, T1 to T2, is of interest (e.g., 12-24 $\mathrm{h}$ outages which is the first compensation level in the Swedish legislation), this is provided by calculating $R_{T 1}-R_{T 2}$.

\section{Conditional Reliability Indices}

Well-established reliability indices, SAIDI, SAIFI, CAIDI, and AENS [18], are used to analyze a system state at a time, "conditional" reliability indices are calculated:

$$
[\text { reliability index }]^{[S]}=[\text { reliability index }] \mid[\text { state } S] .
$$

For example: $\mathrm{SADI} I^{\text {wind speed } \geq 8 \mathrm{~m} / \mathrm{s}}$ represents the average outage time per year and customer, given one theoretical year of wind speed above $8 \mathrm{~m} / \mathrm{s}$. In reality, this state is rare and ought to be calculated based on input data from several years. If $Y \%$ of $S A I D I$ can be traced to state $S$, then

$\mathrm{SAIDI}^{S}[$ hours/year, customer | State $S]=\frac{0.01 Y * \mathrm{SAIDI}}{P(S)}$ where $P(S)$ is the probability of state $S$.

\section{E. Examples of How to Estimate Costs Based on Indices}

A template cost based on the quality function in the Swedish tariff regulation, used by Fortum Distribution (see Section IV-A), is $\sim 18 \$$ per hour and customer, i.e.,

\section{Outage cost}

$$
\approx 18 * \mathrm{SAIDI} * \text { Number of customers [\$/year]. }
$$

Longer outages, 12-24 h, can roughly be translated into economic measures (see Section III-C, Table I), for example:

$$
\begin{aligned}
& \text { Cost }_{12-24} \text { hour outages } \\
& \approx 0.5 *\left(R_{12}-R_{24}\right) * \text { num. of cust. [\$/year]. }
\end{aligned}
$$

In (4), relatively small customers in average are assumed. Outages above $24 \mathrm{~h}$ (i.e., $\mathrm{R}_{24}$ ), however, are difficult to translate into cost because of its double legal consequences. For the U.K. system, $R_{18}$ can roughly be translated to $\sim \$ 0.1 /$ domestic customer, year and $\sim \$ 0.2 /$ non-domestic customer, year (normal weather and 12-42 h outages are assumed). The DSOs could also have own policies motivated by, e.g., goodwill. Using equations introduced in this section, cost reduction of reliability improvements can be estimated.

\section{F. Statistical Validity}

Using reliability indices in different contexts applied to power distribution is well-established. However, these indices could be based on few measurements followed by a high statistical uncertainly, especially the new category of indices, $R_{T}$, introduced in this paper. Therefore, a statistical model is proposed on evaluating reliability indices as a function of amount of input data.
During a defined period, a stochastic amount of reported outages occur and the reliability indices can thus be written as

$$
Z=c \sum_{i=1}^{X} Y_{i}=c X \sum_{i=1}^{X} Y_{i} / X=c X \bar{Y}, \text { where }
$$

- $\mathrm{Z}$ is a stochastic variable representing an index,

- $c(>0)$ is a constant;

- $X$ is a stochastic variable representing the number of measurements;

- $Y_{i}$ is a reading (i.e., numerical value) from the $i$ th measurement in which all $Y_{i}$ are assumed to be mutually independent, equally distributed stochastic variables with expected value $\mu_{Y}>0$, and $\bar{Y}$ is the mean value of all $Y_{i}$.

Suppose that the outcome of $X$ becomes $m$ reported outages of a certain category; then the following can be assumed:

$$
X \in P o(m), \text { where } E(X)=m \text { and } \sigma_{X}=\sqrt{m} \text {. }
$$

For large $m$, the following approximations can be made:

$$
X \in N(m, \sqrt{m}) \text { and } Z \approx c \mu_{Y} X \in N\left(\mu_{Z}, \frac{\mu_{Z}}{\sqrt{m}}\right)
$$

where $\mu_{Z}$ is defined as $c \mu_{Z} m$. One appropriate measure of uncertainty for stochastic variables is the coefficient of variation, $c_{V}$, which is defined as the ratio of standard deviation and expected value:

$$
c_{V}=100 \frac{\frac{\mu_{Z}}{\sqrt{m}}}{\mu_{Z}}=\frac{100}{\sqrt{m}}[\%]
$$

$C_{V}$ is calculated for each analysis in this study. Statistical analysis can be performed, such as, for instance, a 95\% confidence interval can be calculated as

$$
\mu_{Z} \pm 1.96 c_{V} \mu_{Z}
$$

\section{CASE Study}

\section{A. System Reliability/Vulnerability}

According to current Swedish legalization, SAIDI, $\mathrm{R}_{12}$, and $\mathrm{R}_{24}$ are the most important indices to consider. Consequently, in this case study, "vulnerability" and "reliability" are referred to these indices. Results from other reliability indices are also appended because this can differ between countries.

\section{B. Empirical Data}

Two power distribution systems and their associated weather statistics are included in the study. Input data was obtained from the distribution system owned by Gävle Energi AB (DS1) situated in Gästrikland and the other owned by Fortum Distribution, situated in the district of Värmland (DS2); see Fig. 1. Outage data has been collected for 2001-2008. Hourly weather measurements (snow depth every $24 \mathrm{~h}$ ) for the two areas were obtained from the Swedish Meteorological and Hydrological Institute (SMHI), at the weather stations Film and Sunne, respectively, see Fig. 1, selected in consultation with SMHI based on quality and proximity. The weather differs somewhat within 

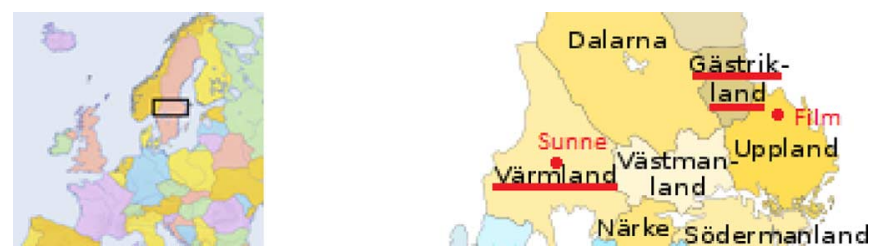

Fig. 1. Middle part of Sweden.

each area, especially between coastal and inland areas for DS1 and between the western upland and the east for DS2.

For DS1, 1851 outages above $0.05 \mathrm{~h}$ were reported and for DS2 the number was 60050 . During the studied period, two severe weather events occurred in Sweden:

- The storm "Gudrun" 8-9 January 2005: Seven days in this study are linked to the storm to capture delayed reported outages.

- The storm "Per" and additional severe weather events in January 2007: Ten days in this study are linked to this weather event.

DS1 has about 50000 and DS2 about 150000 customers. By using (3)-(4) (see Section III-E) knowing number of customers, the economic consequences are estimated to

$$
\begin{aligned}
C_{\mathrm{DS} 1} \approx & 900 * \mathrm{SAIDI} \\
& +25 *\left(R_{12}-R_{24}\right)+\dagger * R_{24}[1000 \$ / \mathrm{yr}] \\
C_{\mathrm{DS} 2} \approx & 2700 * \mathrm{SAIDI} \\
& +75 *\left(R_{12}-R_{24}\right)+\dagger * R_{24}[1000 \$ / \mathrm{yr}] .
\end{aligned}
$$

The consequences, $\dagger$, of $R_{24}$ are difficult to estimate since these outages are forbidden by the Swedish law from 2011.

\section{Time Categories}

Analyses have been performed to determine how the outages are distributed among different periods of time. Fig. 2 exemplifies results from the case study for DS2 for unplanned outage durations. The contribution from the two major weather events that occurred during the analyzed period is shown in the figure. Fig. 2 clearly illustrates how individual weather events can affect the average values of several years.

Knowledge of differing expected reliability parameters between time periods can be used to evaluate whether a DSO has an adequate level of preparedness for inconvenient working hours and when it is appropriate to schedule preventive maintenance. An example of how the results could be used in practice is provided in Section V.

Tables II (DS1) and III (DS2) show SAIDI divided among different months. Knowing the expected reliability on a monthly basis is useful for the planning of maintenance and holidays. The differences between months are probably explained by weather and human activities. Both systems have lowest SAIDI during February-May (in Sweden, lightning mostly occurs during summer). In DS2, the risk based on SAIDI is elevated during November to January. This illustrates a benefit of performing the analysis, since it identified problematic time periods. Resources could, e.g., be allocated for maintenance in
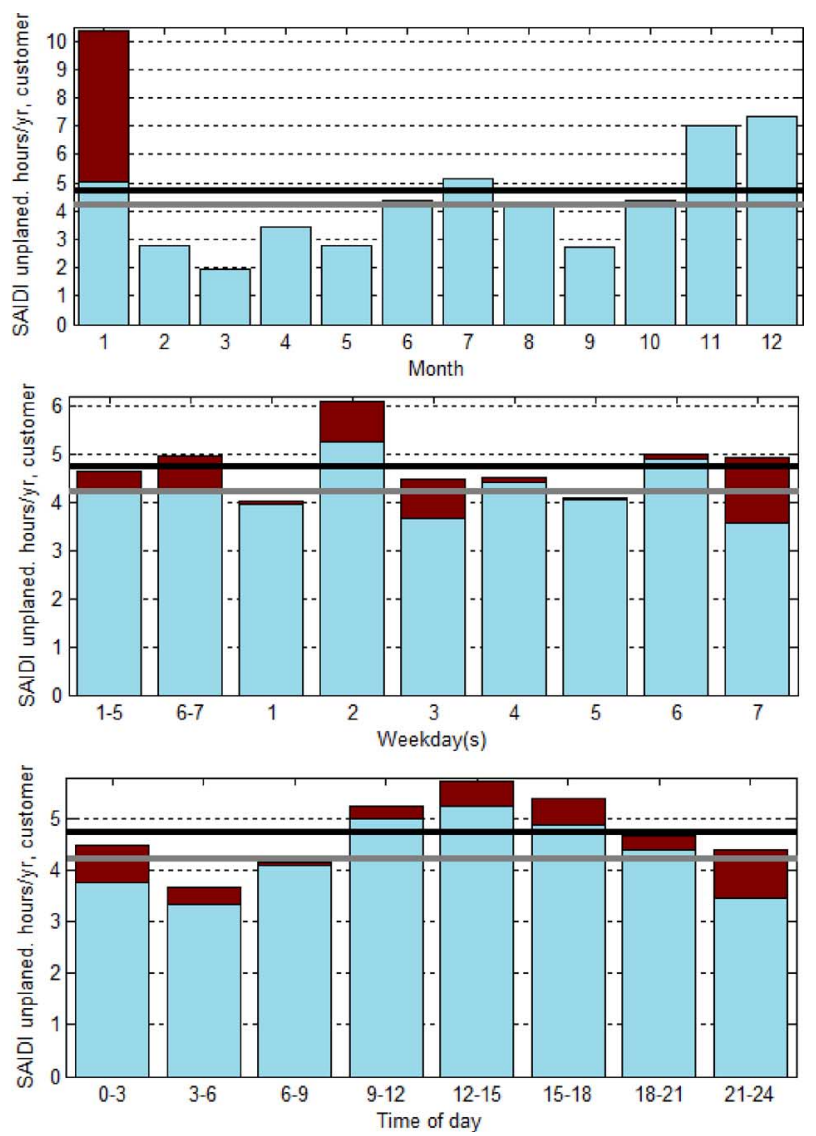

Fig. 2. SAIDI for DS2: unplanned outages divided into months, weekdays, and time of day for 2001-2008. The combined contributions of Per and Gudrun are illustrated with a different color at the top of each bar. The black line is average

\begin{tabular}{|c|c|c|c|c|c|c|c|c|c|c|c|c|c|c|c|}
\hline \multirow[t]{2}{*}{$\overline{\bar{z}}$} & $\stackrel{\widehat{\approx}}{\Xi}$ & 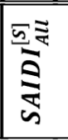 & 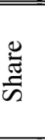 & 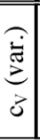 & $\frac{\sqrt[n]{5}}{\overline{5}}$ & 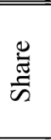 & $\begin{array}{l}\dot{\vec{Z}} \\
\vec{\Xi} \\
\vec{J}\end{array}$ & $\frac{\sqrt[n]{\pi}}{\sqrt{\pi}}$ & $\frac{\sqrt{5}}{5}$ & 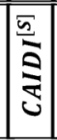 & $\frac{\bar{n}}{2} \approx$ & $\frac{\tilde{\Xi}}{\tilde{n}}$ & $\begin{array}{l}\stackrel{ \pm}{*} \\
己\end{array}$ & 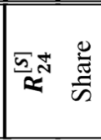 & है \\
\hline & $\overline{8}^{2}$ & * & $\delta^{2}$ & $0^{\circ}$ & * & 5 & $8^{\circ}$ & * & * & * & $*$ & $8^{\circ}$ & $\sqrt{8}$ & $\overline{8}$ & 58 \\
\hline All & 100 & 0.41 & 100 & 2 & 0.2 & 100 & 3 & 0.7 & 3.3 & 0.5 & 1.9 & 100 & 8 & 0.5100 & 0 \\
\hline 1 & 8.5 & 0.4 & 10 & 9 & 0.4 & 14 & 11 & 0.6 & 0 & 0.7 & 0.3 & 1 & 32 & 0.3 & 535 \\
\hline 2 & 7.7 & 0.2 & 3 & 11 & 0.1 & 5 & 13 & 0.5 & 3 & 0.3 & 0.3 & 1 & 41 & 0.3 & 541 \\
\hline 3 & 8.5 & 0.3 & 8 & 9 & 0.2 & 7 & 13 & 1.0 & 1.8 & 0.3 & 0.6 & 2 & 32 & 0.3 & 633 \\
\hline 4 & 8.2 & 0.3 & 7 & 7 & 0.1 & 5 & 11 & 0.5 & 2.8 & 0.7 & 0.4 & 2 & 32 & 0.4 & 732 \\
\hline 5 & 8.5 & 0.3 & 8 & 7 & 0.2 & 6 & 12 & .4 & 3.3 & 0.7 & 0.3 & 1 & 41 & 0.3 & $\begin{array}{ll}6 & 4\end{array}$ \\
\hline 6 & 8.2 & 0.6 & 15 & 6 & 0.4 & 14 & 10 & 1.7 & 3.8 & 0.4 & 1.1 & 5 & 26 & $0.9 \quad 16$ & $\begin{array}{lll}627 \\
\end{array}$ \\
\hline 7 & 8.5 & 0.2 & 4 & 9 & 0.1 & 6 & 11 & 0.9 & 0.6 & 0.2 & 3.9 & 18 & 26 & 0.4 & 730 \\
\hline 8 & 8.5 & 0.2 & 5 & 10 & 0.1 & 5 & 12 & 0 & 2.9 & & 0.6 & 2 & 26 & 0.5 & 828 \\
\hline 9 & 8.2 & 0.3 & 6 & 10 & 0.1 & 4 & 13 & 0.5 & 5.2 & & 0.7 & 3 & 28 & 0.5 & 830 \\
\hline 10 & 8.5 & 0.4 & 9 & 8 & 0.3 & 10 & 10 & 0. & 5.7 & 0.9 & 12.5 & 56 & 22 & $0.8 \quad 14$ & 142 \\
\hline 11 & 8.2 & 0.7 & 16 & 9 & 0.5 & 17 & 10 & 0.8 & 6.3 & & 1.1 & 5 & 23 & $\begin{array}{ll}0.8 & 14\end{array}$ & 1426 \\
\hline 12 & 8.5 & 0.3 & 8 & 9 & 0.2 & 7 & 11 & 0.8 & 2.5 & 0.4 & 0.6 & 3 & 29 & 0.4 & 633 \\
\hline
\end{tabular}
SAIDI, grey line is average SAIDI with Per and Gudrun excluded.

TABLE II

DS1-VuLNERABILITY With RESPECT TO DIFFERENT MONTHS

the spring and holidays scheduled primarily for late summer, while November to January might require extra resources.

Knowing the expected reliability of weekdays or time of day may, for example, be useful in determining the readiness needed during shifts. The differences between weekdays showed in Tables IV (DS1) and V (DS2) might be explained by human 
TABLE III

DS2-VuLNERABILITY WITH RESPECT TO DIFFERENT MONTHS

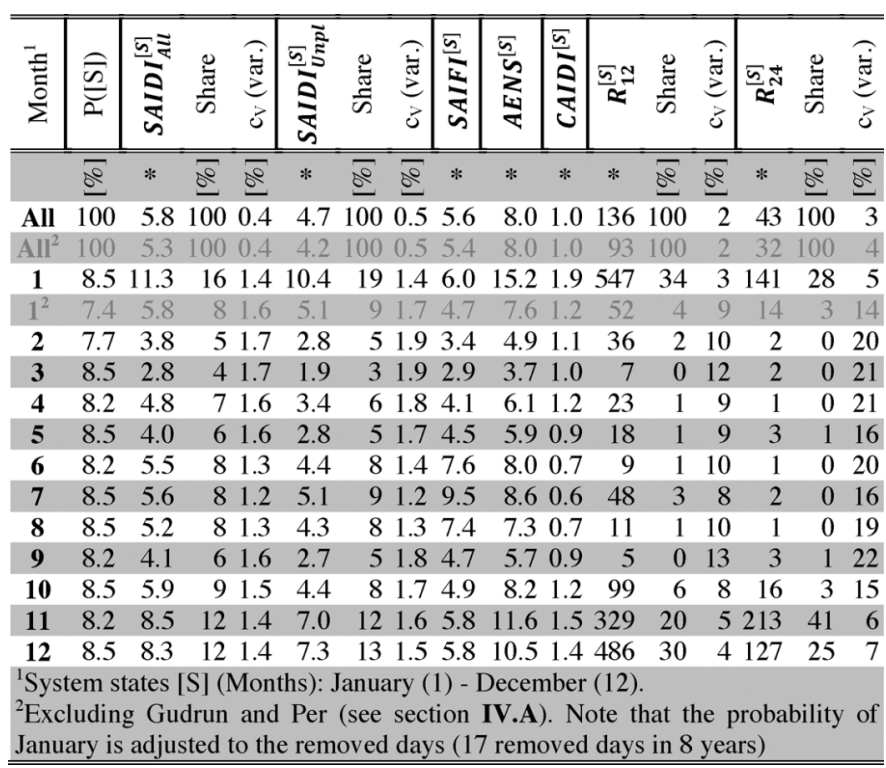

TABLE IV

DS1-VULNERABILITY WITH RESPECT TO WEEKDAYS

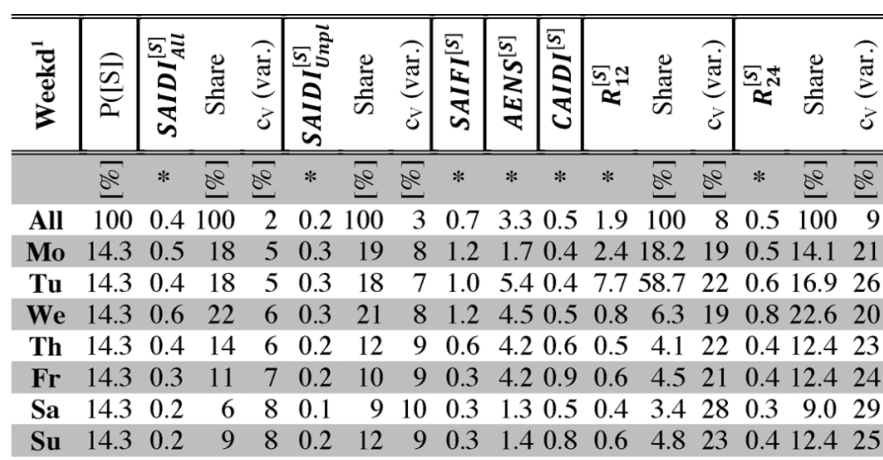

WD $71.4 \begin{array}{lllllllllllllllll}0.4 & 84 & 3 & 0.3 & 80 & 4 & 0.9 & 4.0 & 0.5 & 2.4 & 91.8 & 9 & 0.5 & 78.5 & 10\end{array}$

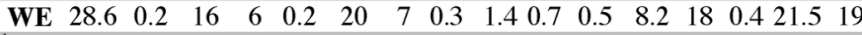
${ }^{1}$ System states [S] (Weekdays): Monday (Mo) - Sunday (Su) and workday (WD, i.e. Mo-Fr) and weekend (WE, i.e. Sa-Su).

activities and the security level. If the reliability differs between days, the DSO could consider reallocate existing resources. For outages during non-"normal" working hours, the lowest SAIDI is between approximately 03-06 AM. See Tables VI and VII. The causes of the differences have not been studied in detail, but load and human activity are likely explanations based on experiences and discussions with the DSOs.

\section{Weather Categories}

Dependencies and Correlations: For the analysis of weather conditions, it is important to establish whether any results are due to actual causation. A first step is to calculate the correlation between weather parameters, which is shown in Table VIII. Some weather parameters could also correlate with the electrical consumption. In Sweden, a strong negative correlation between temperature and power demand has been identified in an earlier
TABLE V

DS2-VULNERABILITY WITH RESPECT TO WEEKDAYS

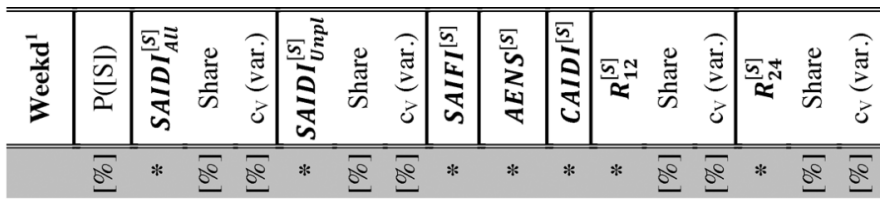

$\begin{array}{lllllllllllllllllll}\text { All } & 100 & 5.8 & 100 & 0.4 & 4.7 & 100 & 0.5 & 5.6 & 8.0 & 1.0 & 136 & \overline{100} & 2 & 43 & 100 & 3\end{array}$ $\begin{array}{lllllllllllllllll}\text { Mo } & 14.3 & 5.1 & 12 & 1.0 & 4.0 & 12 & 1.1 & 5.8 & 6.8 & 0.9 & 35 & 4 & 5 & 7 & 2 & 7\end{array}$ $\begin{array}{llllllllllllllllll}\text { Tu } & 14.3 & 8.3 & 20 & 1.0 & 6.1 & 18 & 1.1 & 7.0 & 10.8 & 1.2 & 123 & 13 & 5 & 21 & 7 & 8\end{array}$ $\begin{array}{llllllllllllllllll}\text { We } & 14.3 & 6.2 & 15 & 1.1 & 4.5 & 14 & 1.2 & 5.8 & 8.0 & 1.1 & 46 & 5 & 6 & 5 & 2 & 9\end{array}$ $\begin{array}{llllllllllllllllll}\text { Th } & 14.3 & 6.3 & 15 & 1.0 & 4.5 & 14 & 1.2 & 6.1 & 8.4 & 1.0 & 178 & 19 & 5 & 113 & 38 & 8\end{array}$ $\begin{array}{llllllllllllllllll}\text { Fr } & 14.3 & 4.8 & 12 & 1.1 & 4.1 & 12 & 1.2 & 5.2 & 6.7 & 0.9 & 127 & 13 & 6 & 40 & 13 & 9\end{array}$ $\begin{array}{lllllllllllllllll}\text { Sa } & 14.3 & 5.1 & 13 & 1.3 & 5.0 & 15 & 1.3 & 4.7 & 8.1 & 1.1 & 271 & 28 & 5 & 71 & 24 & 7\end{array}$ $\begin{array}{lllllllllllllllll}\text { Su } & 14.3 & 5.0 & 12 & 1.3 & 4.9 & 15 & 1.3 & 4.3 & 7.2 & 1.2 & 172 & 18 & 5 & 43 & 14 & 7\end{array}$

$\begin{array}{llllllllllllllllll}\text { WD } & 71.4 & 6.1 & 75 & 0.5 & 4.6 & 70 & 0.5 & 6.0 & 8.1 & 1.0 & 102 & 53 & 2 & 37 & 62 & 4\end{array}$

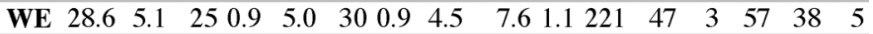
${ }^{1}$ System states [S] (Weekdays): Monday (Mo) - Sunday (Su) and workday (WD, i.e. Mo-Fr) and weekend (WE, i.e. Sa-Su).

TABLE VI

DS1-VULNERABILITY WiTH RESPECT TO TIME OF DAY

\begin{tabular}{|c|c|c|c|c|c|c|c|c|c|c|c|c|c|c|c|}
\hline 总 & 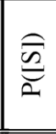 & 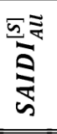 & $\begin{array}{l}\frac{\mathscr{U}}{\tilde{*}} \\
\frac{\pi}{n}\end{array}$ & & 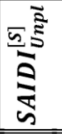 & 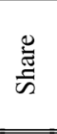 & $\begin{array}{l}\vec{z} \\
\vec{Z} \\
3\end{array}$ & $\frac{\sqrt[n]{n}}{\frac{n}{\pi}}$ & 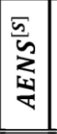 & 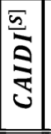 & $\bar{n} \cong$ & 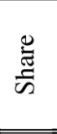 & $\begin{array}{l}\stackrel{ \pm}{ \pm} \\
3 \\
0\end{array}$ & 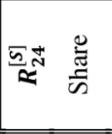 & \\
\hline [hrs] & 2 & * & 8 & se & * & $\overline{2}$ & 2 & * & 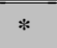 & $*$ & * & 5 & $a^{2}$ & $\overline{2}$ & $\pi$ \\
\hline All & 100 & 1 & 100 & 2 & 0.2 & 100 & 3 & 0.7 & 3.3 & 0.5 & 1.9 & 100 & 8 & $\begin{array}{lll}0.5 & 100\end{array}$ & \\
\hline $0-3$ & 12.5 & . & 12 & 13 & 0.3 & 15 & 14 & 0.3 & & 1.2 & 2.61 & 17.5 & 41 & 0.411 .3 & \\
\hline 3-6 & 12.5 & & 6 & 14 & 0.1 & 7 & 16 & 3 & & 0.6 & 0.0 & 0.3 & 71 & 1.1 & \\
\hline & 5 & & 8 & 7 & 2 & 9 & 9 & 5 & & 0.5 & 0.7 & 4.5 & 26 & 0.513 .0 & \\
\hline $9-12$ & 5 & 0 & 22 & 4 & 0.2 & 13 & 7 & 0 & & 0.6 & 0.6 & 3.6 & 24 & 0.41 & \\
\hline & 5 & 0.6 & 20 & 6 & 0.3 & 18 & 8 & 1.7 & & 0.3 & 0.9 & 6.0 & 19 & 0.8 & \\
\hline & 2.5 & 0.3 & 12 & 7 & 0.3 & 14 & 7 & 0.5 & 3.2 & 0.6 & 1.1 & 7.3 & 15 & 0.922 .0 & \\
\hline & 12.5 & 3 & 9 & 8 & 0.2 & 12 & 9 & 0.8 & & & 1.1 & 7.6 & 18 & 0.716 .9 & \\
\hline 4 & 12.5 & 03 & 11 & 10 & 0.2 & 11 & 11 & 0.5 & 1.5 & 0.6 & 8.05 & 53.1 & 33 & $0.2 \quad 4.0$ & \\
\hline
\end{tabular}

TABLE VII

DS2-VULNERABILITY WITH RESPECT TO TIME OF DAY

\begin{tabular}{|c|c|c|c|c|c|c|c|c|c|c|c|c|c|c|c|c|}
\hline 苂 & $\widehat{\widehat{\cong}}$ & $\frac{n}{\sqrt[n]{2}}$ & 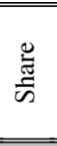 & 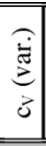 & 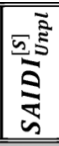 & 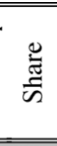 & $\begin{array}{l}\dot{\vec{E}} \\
\vec{己} \\
\dot{0}\end{array}$ & $\frac{\frac{5}{2}}{\frac{5}{5}}$ & 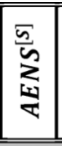 & 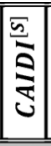 & $\overline{\tilde{n}} \approx$ & 营 & 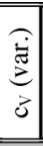 & $\frac{\bar{n}}{2} \approx$ & $\frac{\mathscr{E}}{\tilde{W}}$ & \\
\hline rs] & be & & $8^{\circ}$ & 6 & * & 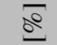 & 8 & $*$ & * & $*$ & * & 8 & $\overline{8}$ & & $\therefore$ & \\
\hline All & 100 & 5.8 & 100 & 0.4 & 7 & 100 & 0.5 & 5.6 & 8.0 & & 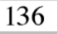 & 100 & 2 & 43 & 100 & \\
\hline 0 . & 5 & 4.7 & & & 5 & 12 & 2.3 & & & & 210 & 19 & 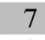 & 0 & 12 & \\
\hline $3-6$ & & 3.8 & & 2 & 7 & & 2.1 & & & 1 & 58 & 6 & 13 & 12 & & \\
\hline 6- & & 5.9 & 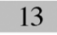 & & 2 & & 3 & 5.4 & 8.4 & 1.1 & 38 & 4 & & 0 & & \\
\hline $9-12$ & 2.5 & 1 & 24 & & 3 & & & 8.6 & 5 & 1.3 & 204 & 19 & & 127 & 37 & \\
\hline 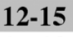 & 12.5 & 6.2 & 13 & 1.0 & 5.7 & & & 7.6 & 8.7 & 0.8 & 129 & 12 & 5 & 52 & 15 & \\
\hline & 1 & 5.5 & 12 & & 5.4 & 4 & & 7.0 & 7.3 & 0.8 & 74 & & 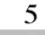 & 3 & 7 & \\
\hline & 12.5 & 4.7 & 10 & 1.2 & 4.7 & 2 & & 5.8 & 6.5 & 0.8 & 91 & 0 & 5 & 10 & 3 & \\
\hline & 5 & 4.6 & & 1 & 4.4 & 12 & & 3.9 & 6.4 & 1.2 & 285 & 26 & 3 & 70 & 21 & \\
\hline
\end{tabular}

study [19], also seen in Table VIII. Hence, any temperature-related results might as well depend on the load and vice versa. There is a risk to underestimate the total energy not supplied if mean values are used because outages are more likely to occur during high load in winter, whatever the cause (higher risk of storms, high load, frost, etc.) [20]. A low correlation does not automatically mean independency. For example, temperatures around $0^{\circ} \mathrm{C}$ increase the likelihood of strong winds, while both 
TABLE VIII

CORRELATIONS BETWEen WEATHER EVENTS

\begin{tabular}{lcrr}
\hline \hline & Temperature & \multicolumn{1}{l}{ Wind speed } & Precipitation \\
\hline${ }^{1}$ Wind speed & $0.14 / 0.20$ & & \\
\hline${ }^{1}$ Precipitation & $0.03 / 0.07$ & $0.09 / 0.11$ & \\
\hline${ }^{1}$ Snow depth & $-0.58 /-0.50$ & $0.00 / 0.20$ & $0.00 / 0.07$ \\
\hline${ }^{2}$ E. consumption & $-0.90^{3}$ & 0.03 & not available \\
\hline${ }^{1}$ area DS1\}/ area DS2 $\}$ & & \\
${ }^{2}$ These statistics are from an study performed in Sweden [19] & \\
${ }^{3}$ The negative correlation drops below $-20^{\circ} \mathrm{C}$ & & \\
\hline \hline
\end{tabular}

\section{Effects on major weather events}
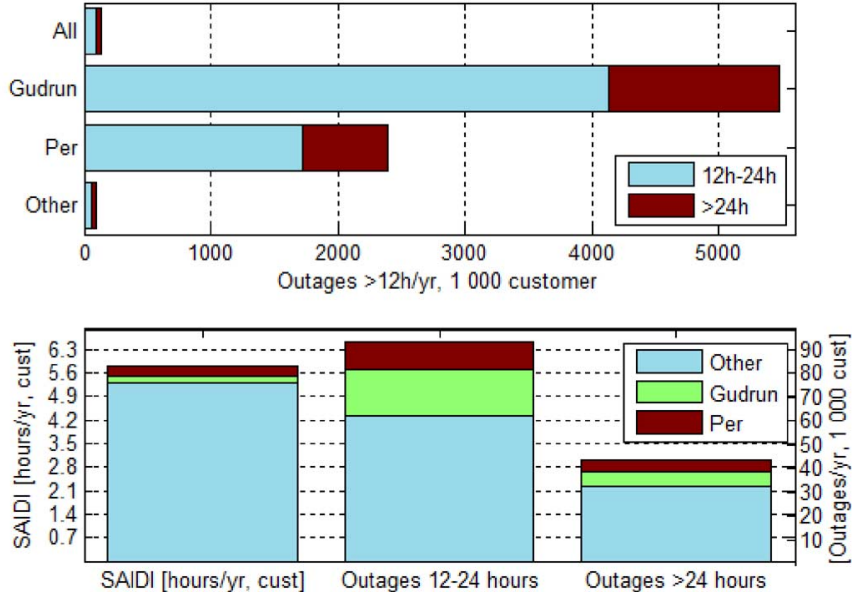

Fig. 3. DS2: the contribution from two single major weather events during a period of eight years. The upper figure presents conditional values given a specific state. The lower figure is in absolute average values.

TABLE IX

DS2-VULNERABILITY WITH RESPECT TO MAJOR STORMS

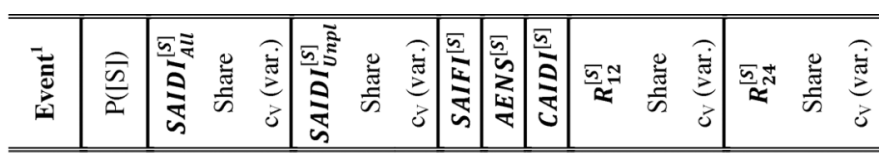

[hrs] इ্ $\begin{array}{lllllllllllllllllllllll}\text { All } & 100 & 5.8 & 100 & 0.4 & 4.7 & 100 & 0.5 & 5.6 & 8.0 & 1.0 & 136 & 100 & 2 & 43 & 100 & 3\end{array}$

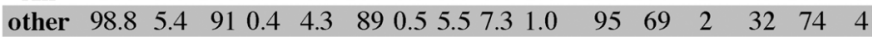

$\begin{array}{lllllllllllllllll}\text { Gudr } & 0.5 & 38 & 3 & 4.6 & 38 & 4 & 4.7 & 11 & 47 & 3.3 & 5475 & 19 & 6 & 1336 & 15 & 9\end{array}$ $\begin{array}{llllllllllllllll}\text { Per } & 0.7 & 49 & 6 & 3.6 & 48 & 73.7 & 16 & 75 & 3.0 & 2392 & 12 & 5 & 664 & 11 & 7\end{array}$ ${ }^{1}$ System states [S] (event): other, Gudrun (Gudr) and Per.

low and high temperatures often occur during high pressure with low wind speeds.

Effects on Major Weather Events: The contribution from the two severe weather periods listed in Section IV-A has only marginally affected the results of DS1. The contribution in DS2 is, however, large: see Table IX and Fig. 3. About $20 \%$ of all outages $\geq 12 \mathrm{~h}$ occurred during Gudrun. Per also contributed to a significant share of the long outages, but, compared with $\mathrm{Gu}$ drun, had more impact on SAIFI, which might be explained by better preparedness, as an effect of experience gained from $\mathrm{Gu}-$ drun.

Wind Speed: Wind speed ranges are determined in accordance with the Beaufort scale [21]. The results in Table X show that the system's vulnerability according to SAIDI and SAIFI as well as outages $>12 \mathrm{~h}$, is in principle independent of wind speed most of the time. The results for DS2, Table XI and Fig. 4, indicate an increased risk over a wider wind speed range. One
Wind speed
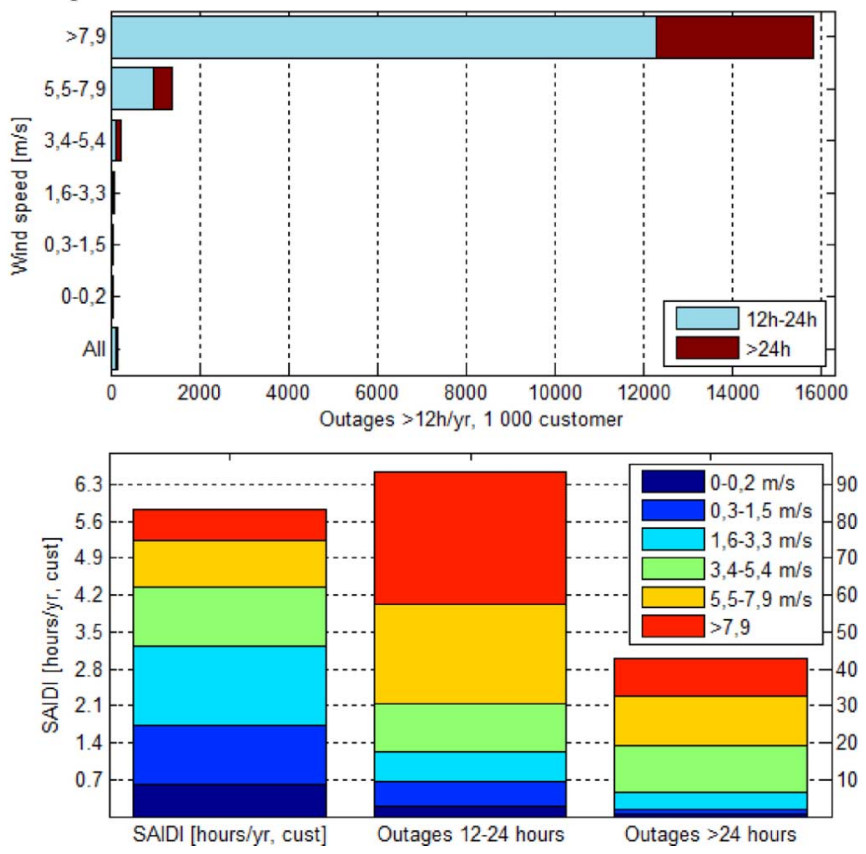

Fig. 4. DS2: indication of the vulnerability of strong wind.

TABLE $X$

DS1-VulNERABILITY With RESPECT TO WIND SPEED

\begin{tabular}{|c|c|c|c|c|c|c|c|c|c|c|c|c|c|}
\hline E & $\stackrel{\overline{\mathscr{n}}}{\stackrel{2}{=}}$ & $\frac{\sqrt[n]{\pi}}{\bar{\sigma}}$ & 䔍 & 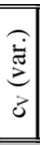 & 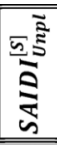 & $\frac{\mathscr{J}}{\tilde{W}}$ & 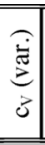 & $\frac{5}{5}$ & $\sum_{\substack{5 \\
y}}^{\frac{5}{5}}$ & $\mid$ & 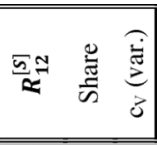 & $\begin{array}{l}\bar{n} \\
\approx \\
\approx\end{array}$ & \\
\hline & $\overline{8}$ & * & $0^{\circ}$ & $b^{\circ}$ & * & 8 & 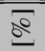 & $*$ & * & * & $\overline{5}$ & 2 & os \\
\hline all & 100 & 0.41 & 100 & 2 & 0.2 & 100 & 3 & 0.7 & 3 & 0.5 & 1.9100 & 0.5100 & \\
\hline 1 & 12 & 0.2 & 5 & 10 & 0.1 & 5 & 11 & 0.2 & 2 & 1.0 & $\begin{array}{llll}2.6 & 16 & 0.2\end{array}$ & 0.3 & 2 \\
\hline 2 & 20 & 0.4 & 20 & 5 & 0.2 & 20 & 8 & 1.0 & & 0. & 50.2 & $0.4 \quad 16$ & \\
\hline 3 & 37 & 0.3 & 30 & 4 & 0.2 & 29 & 6 & 0.5 & 5 & ( & 150.1 & $0.5 \quad 36$ & \\
\hline 1 & 24 & 0.3 & 21 & 5 & .2 & 16 & 7 & 0.7 & & 0.4 & .2 & $\begin{array}{ll}5 & 25\end{array}$ & \\
\hline 5 & 6 & 5 & 9 & 8 & 0.4 & 10 & 11 & 0 & & 0 & .4 & 7 & \\
\hline 6 & 1 & 0.0 & 13 & 13 & 6.3 & 19 & 14 & 0.0 & & 1.0 & $\begin{array}{crr}148.0 & 53 & 0.4\end{array}$ & 3.6 & \\
\hline 7 & & 20.3 & 3 & & 1.5 & 3 & 35 & 58.7 & 14.0 & & 10.7 & 36.5 & \\
\hline
\end{tabular}

TABLE XI

DS2-VULNERABILITY WITH RESPECT TO WIND SPEED

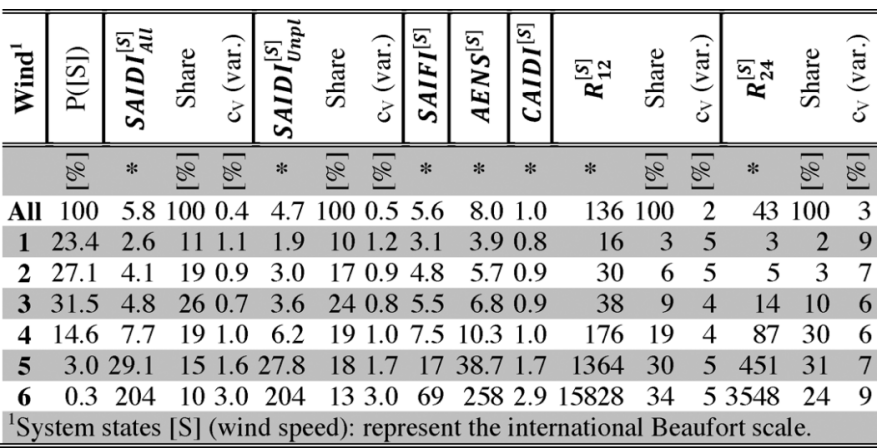

explanation could be that the area is larger, so that data from the single weather station is less representative.

Temperature and High Load: The results presented in Table XII show no clear connection between reliability and temperature or power consumption. The results of DS1 are 
TABLE XII

DS2-VULNERABILITY WITH RESPECT TO TEMPERATURE

\begin{tabular}{|c|c|c|c|c|c|c|c|c|c|c|c|c|c|c|c|}
\hline 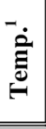 & $\stackrel{\widehat{\omega}}{\widetilde{c}}$ & $\frac{n}{\bar{n}}$ & 莺 & 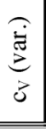 & 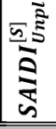 & 总 & $\begin{array}{l}\tilde{E} \\
3\end{array}$ & $\frac{5}{5}$ & 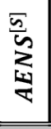 & $\frac{\frac{5}{\pi}}{\frac{\pi}{3}}$ & $\frac{5}{\alpha} \approx$ & & $\begin{array}{l}\frac{\pi}{3} \\
3\end{array}$ & 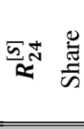 & \\
\hline C & $\overline{8}$ & * & 89 & 8 & * & $\underline{9}$ & 89 & * & * & $*$ & * & & o & 5 & \\
\hline All & 100 & 5.8 & 100 & 0.4 & 4.7 & 100 & 5 & 6 & 8.0 & 1.0 & 13610 & 00 & 2 & 43100 & 0 \\
\hline-30 & 0.0 & 4.6 & 0.0 & 57.7 & 4.6 & 0.0 & 57.7 & 9 & 8.8 & 24 & 0 & 0 & $\infty$ & c & 0 \\
\hline-25 & 0.1 & 3.9 & 1 & 10.4 & 3.9 & 0.1 & 10 & 4.0 & & 1 & 1 & & 100 & & 0 \\
\hline-20 & 0.6 & 3. & 0.3 & 9 & 3.3 & 4 & 6.0 & 3 & & 1 & & & 71 & & \\
\hline-15 & 1.7 & 1.8 & 0.5 & 8 & 2 & + & 4 & 1.3 & 2.5 & 1 & 3 & 0 & 24 & & 0 \\
\hline-10 & 4.1 & 2. & & 5 & 1 & 1 & & 1 & & 1.1 & 12 & & 16 & & \\
\hline-5 & 9.9 & 3. & 5.3 & 6 & 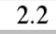 & 4.5 & 1.8 & 2.8 & & 1.1 & 25 & & 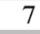 & & 2 \\
\hline & 21.2 & 6.72 & 24.5 & .0 & 8 & 25.8 & 1.1 & 0 & 9.0 & 1.4 & 279 & 43 & 3 & $\begin{array}{ll}78 \quad 39 \\
\end{array}$ & 39 \\
\hline & 18.7 & 6 & 21.7 & 0 & 6 & 22.2 & 1.1 & 1 & 4 & 1 & 2072 & 28 & 3 & $\begin{array}{ll}51 \quad 22\end{array}$ & \\
\hline 10 & 18.5 & 6 & 21.2 & 0 & & 2 & 1.1 & 5.6 & & & 154 & 21 & 5 & $80 \quad 35$ & 35 \\
\hline 15 & 15.8 & 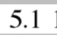 & 13.8 & 9 & 4.0 & 13.2 & & t & & 0.7 & 15 & 2 & 7 & 3 & 1 \\
\hline 20 & 6.9 & 6.6 & 8 & 2 & 5.1 & 5 & 3 & 6 & 9.3 & 0.7 & 59 & 3 & 9 & & 0 \\
\hline 25 & 2.3 & 7.3 & 2.9 & 1 & 6 & 0 & 2 & 9.4 & & & 9 & 0 & 17 & & \\
\hline 30 & 0.2 & 7.9 & 0.3 & 1 & 7.8 & 0.3 & 7.2 & 10.2 & & 0.8 & 1 & 0 & 1 & & \\
\hline
\end{tabular}

TABLE XIII

DS2-VULNERABILITY WITH RESPECT TO SNOW DEPTH

\begin{tabular}{|c|c|c|c|c|c|c|c|c|c|c|c|c|c|c|c|c|}
\hline के & $\widehat{\widehat{\mathscr{\varrho}}}$ & 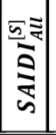 & 产 & 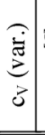 & 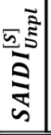 & 䔍 & $\begin{array}{l}\overrightarrow{\tilde{\pi}} \\
\overrightarrow{3} \\
0 \\
0\end{array}$ & $\frac{\frac{5}{2}}{\frac{\pi}{\pi}}$ & 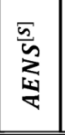 & $\frac{\sqrt[n]{\underline{n}}}{\bar{a}}$ & $\frac{\bar{a}}{2} \approx$ & 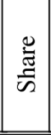 & 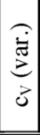 & $\stackrel{\bar{s}}{\approx} \approx$ & & \\
\hline cm & $\overline{8}$ & * & 8 & $\overline{0}$ & * & $\overline{8}$ & $\overline{8}$ & * & * & $*$ & * & $5^{\circ}$ & $\overline{0}$ & * & $\overline{2}$ & 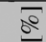 \\
\hline All & 100 & 5.8 & 100 & 0.4 & 4.7 & 100 & 0.5 & 5.6 & 8.0 & 1.0 & 136 & 100 & 2 & 43 & 100 & \\
\hline 0 & 62.9 & 5.3 & 58 & & 4.2 & 55 & 0.6 & 6.0 & 7.6 & 0.9 & 72 & 33 & 3 & 14 & 21 & \\
\hline 0-10 & 20.6 & 7.8 & 27 & & 6.8 & 30 & 1.0 & 5.0 & 10.4 & 1.5 & 385 & 58 & & 156 & 75 & \\
\hline $10-20$ & 7.9 & 4.1 & & 1.6 & 3.2 & 5 & 1.8 & 4.0 & 5.2 & 1.0 & 42 & 2 & 11 & 1 & 0 & \\
\hline $20-30$ & 4.1 & 6.6 & & 2.0 & 5.8 & & 2.2 & 5.4 & 7.8 & 1.2 & 113 & 3 & 11 & 17 & 2 & 22 \\
\hline$>30$ & 4.6 & 5.7 & & 2.1 & 4.8 & & 2.2 & 4.4 & 7.3 & 1.3 & 81 & 3 & 11 & 24 & 3 & \\
\hline
\end{tabular}

TABLE XIV

DS1-VULNERABILITY WITH RESPECT TO SNOW DEPTH

\begin{tabular}{|c|c|c|c|c|c|c|c|c|c|c|c|c|}
\hline के & $\widehat{\widehat{\omega}}$ & 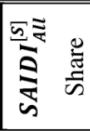 & $\begin{array}{l}\widehat{\dot{E}} \\
\vec{z} \\
z\end{array}$ & 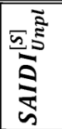 & & $\begin{array}{l}\overparen{\dot{\tilde{N}}} \\
0 \\
0\end{array}$ & 离 & $\sum_{\substack{5 \\
x}}^{\frac{5}{5}}$ & 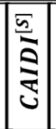 & 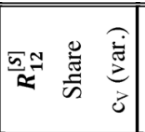 & 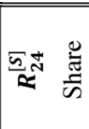 & \\
\hline $\mathrm{cm}$ & 5 & 80 & 20 & * & 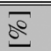 & $\overline{50}$ & * & * & * & 80 & & 80 \\
\hline All & 100 & $0.4 \overline{100}$ & 2 & 0.2 & 100 & 3 & 0.7 & 3.3 & 0.5 & $1.9100 \quad 8$ & 0.5100 & \\
\hline 0 & 71.1 & $0.4 \quad 72$ & 3 & 0.2 & 70 & 4 & 0.6 & .7 & 0.6 & $2.4 \quad 920.1$ & $0.5 \quad 74$ & \\
\hline $0-10$ & 9.2 & $0.4 \quad 11$ & 9 & 0.3 & 11 & 12 & 0.9 & 1.2 & 0.5 & 30.3 & 0.3 & \\
\hline $10-20$ & 9.4 & 0.3 & 9 & 0.2 & 8 & 11 & 0.5 & & 0.5 & 50.2 & $0.8 \quad 16$ & \\
\hline 20-30 & 5.3 & 0.3 & 11 & 0.2 & 5 & 13 & 1.6 & 3.5 & 0.2 & 00.7 & 0.1 & \\
\hline$>30$ & 5.0 & 0.4 & 11 & 0.3 & 7 & 15 & 0.7 & 4.5 & 0.6 & 10.4 & 0.3 & \\
\hline
\end{tabular}

similar and omitted. The outage variations between temperature intervals that exist might be explained by that some weather events are more likely at certain temperatures and human activities, e.g., digging, depends on temperature.

Snow Depth: The results, presented in Tables XIII and XIV, are too mixed and smooth to make any conclusions. Indications of higher risk can be explained by correlations with other weather parameters. The overall indication is however that snow depth has low impact on the reliability.

Precipitation: Measurements of precipitation of the last 24 $\mathrm{h}$ are used in this study. This is motivated by the fact that outages could occur from a chain of events (e.g., snowfall) longer than $1 \mathrm{~h}$. The accumulated $24 \mathrm{~h}$-value is established for every
TABLE XV

DS1-VuLNERABILITY WITH RESPECT TO PRECIPITATION/24 h

\begin{tabular}{|c|c|c|c|c|c|c|c|c|c|c|c|c|c|}
\hline 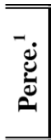 & $\widehat{\overline{\tilde{n}}}$ & 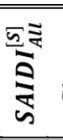 & 这 & & 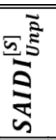 & $\frac{\mathscr{\Xi}}{\tilde{E}}$ & 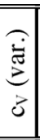 & $\frac{5}{\sqrt[5]{x}}$ & 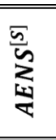 & 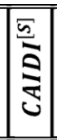 & 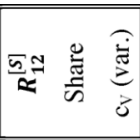 & 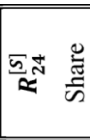 & \\
\hline & $\overline{5}$ & * & $\overline{8}$ & $0^{\circ}$ & * & $\overline{8}$ & $\overline{2}$ & * & * & * & $8^{2} \overline{2}$ & $\overline{50}$ & \\
\hline All & 100 & 0.41 & & 2 & 0.2 & 100 & 3 & 0 & 3.3 & .5 & 1.91008 & 0.5100 & \\
\hline 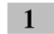 & 99.3 & 0.3 & 92 & 2 & 0.2 & 88 & 3 & 0.7 & 3.3 & 0.5 & $\begin{array}{llll}0.9 & 46 & 0.1\end{array}$ & 0.491 & \\
\hline 2 & 0.6 & 0.3 & & 28 & 0.3 & 1 & 29 & 0 & 5 & 0.6 & $\begin{array}{ll}0 & 0.7\end{array}$ & 0.9 & \\
\hline 3 & 0.1 & 24 & & 24 & 24 & 10 & 2 & 13.6 & 0.4 & & $940 \quad 51$ & 36 & \\
\hline
\end{tabular}

TABLE XVI

DS2-VULNERABILITY WITH RESPECT TO PRECIPITATION/24 h

\begin{tabular}{|c|c|c|c|c|c|c|c|c|c|c|c|c|c|c|c|c|}
\hline 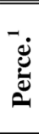 & $\widehat{\bar{\omega}}$ & 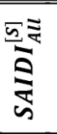 & & $\begin{array}{l}\overparen{\vec{E}} \\
\stackrel{\vec{Z}}{3} \\
0\end{array}$ & 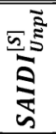 & 芯 & 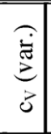 & $\frac{\bar{s}}{\frac{5}{5}}$ & $\begin{array}{l}\frac{5}{5} \\
\sum_{n=1}^{n} \\
y\end{array}$ & 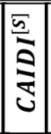 & $\bar{n} \approx$ & 就 & & 高 & 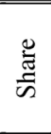 & $\cong$ \\
\hline & 8 & $*$ & 8 & 8 & * & 8 & $\overline{0}$ & $*$ & $*$ & $*$ & $*$ & 8 & 2 & * & $0^{\circ}$ & \\
\hline All & 100 & 5.8 & 100 & & 4.7 & 100 & 0.5 & 5.6 & 8.0 & 1.0 & 136 & 100 & 2 & 43 & 100 & \\
\hline 1 & 94.9 & 4.8 & & 0.4 & 3.7 & & 0.5 & 5.0 & 6.6 & 1.0 & 89 & 62 & ? & 33 & 73 & \\
\hline $2 \mathbf{a}$ & 3.5 & 9.7 & & 1.6 & 8.4 & & 1.7 & 12.6 & 13.3 & 0.8 & 84 & 2 & 9 & 52 & & \\
\hline $2 \mathrm{~b}$ & 0.2 & 90 & & 4.3 & 89.3 & & 4.3 & 44.0 & 117.3 & 2.0 & 8595 & 15 & & 1920 & 10 & \\
\hline 3 & 1.3 & 53 & 11 & 2.3 & 52.0 & 14 & 2.4 & 21.6 & 76.3 & 2.5 & 2172 & 21 & 6 & 419 & 13 & 1 \\
\hline
\end{tabular}

hour. The results of DS1 indicate that precipitation below 20 $\mathrm{mm} / 24 \mathrm{~h}$ (equivalent to $\sim 20 \mathrm{~cm}$ of fresh snow) has no major effect on SAIDI, SAIFI, $\mathrm{R}_{12}$, and $\mathrm{R}_{24}$, i.e., increased vulnerability. In DS2, lower precipitation (10 $\mathrm{mm} / 24 \mathrm{~h}$ set as limit) affects the reliability compared with DS1. This can be explained by a larger area and consequently larger average distance to the weather station. Table XV shows that large amounts of fresh snow increase the risk of both long and short outages. Rain and small amounts of snow have basically no effect at all on DS1. The results for DS2 (Table XVI) also indicate snow as a vulnerable state; however, these results also indicate vulnerability due to rainfall. To investigate the cause, the weather state "rain" is divided into two sub-states based on the wind situation, which show that this "non-intuitive" phenomena correlates with strong winds which could explain.

Weather-Related Risk Categories, Deepened Analysis: The studied power distribution systems are vulnerable to excessive snow, high wind speeds, and single serious weather events. To analyze the influence of these risk categories and causality, a number of system states have been analyzed further; see Tables XVII and XVIII. The results show that only strong winds or heavy snowfall alone increases SAIDI, SAIFI, $\mathrm{R}_{12}$, and $\mathrm{R}_{24}$ and that the combination of the two is more critical than the sum of the individual states. The results of DS1 and DS2 are illustrated in Figs. 5 and 6, respectively.

\section{Discussion On APPLICATION OF the Results}

The tools provided in this paper give indications of effective resource allocation. The focus is more on vulnerability analyses than costs; however, analysis results from presented method can be used to evaluate asset management actions and to improve the utilization of existing resources. In future work, more detailed cost analysis methods will be added. 

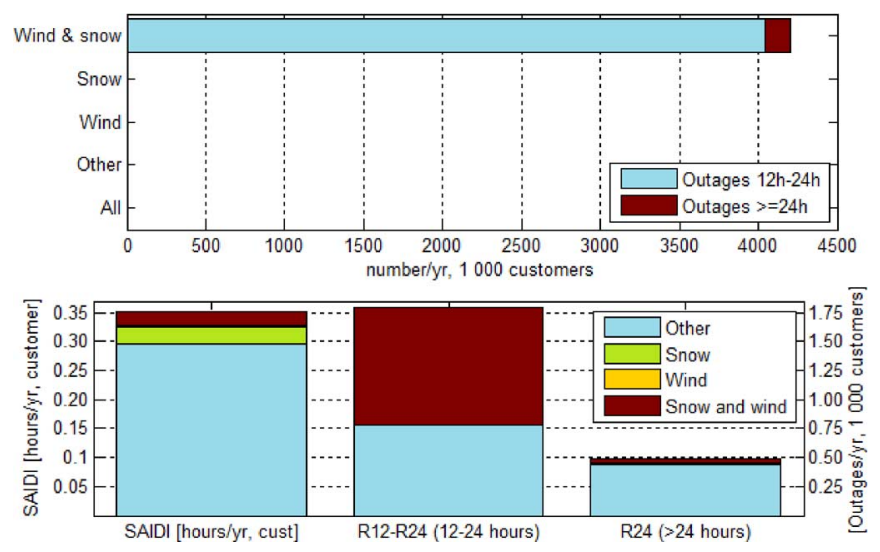

Fig. 5. DS1: vulnerability categories with respect to identified weather categories that provide the highest risk for customer outages.
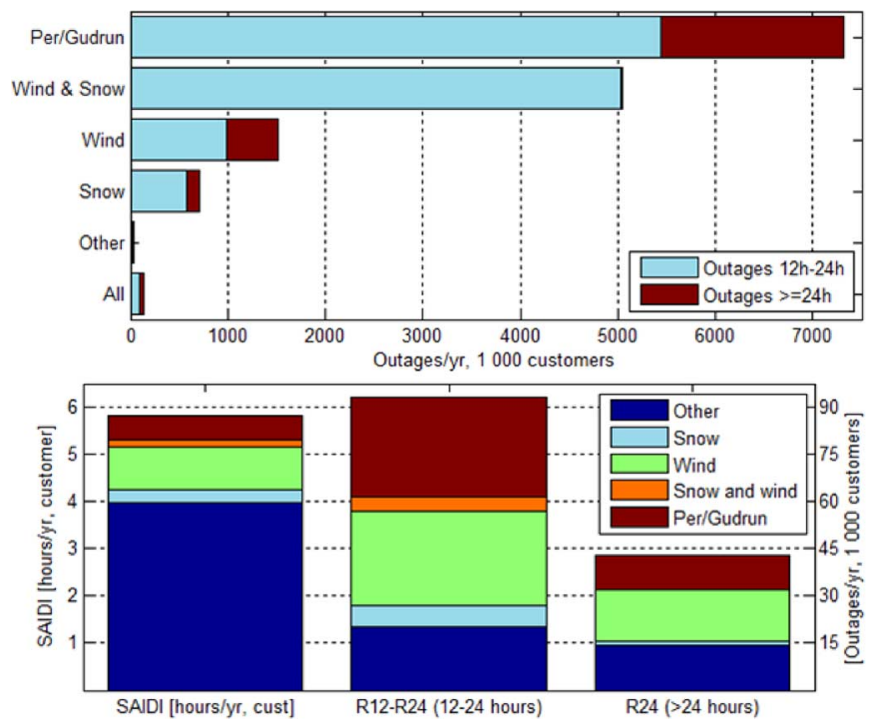

Fig. 6. DS2: vulnerability categories with respect to identified weather categories that provide the highest risk for customer outages.

TABLE XVII

DS1-VULNERABILITY WITH RESPECT TO RISK CATEGORIES

\begin{tabular}{|c|c|c|c|c|c|c|c|c|c|c|c|c|c|c|c|}
\hline$\frac{1}{2}$ & $\widehat{\widehat{a}}$ & $\frac{\sqrt[n]{n}}{\frac{\pi}{2}}$ & $\frac{\mathscr{\Xi}}{\omega}$ & $\begin{array}{l}\overparen{\vec{E}} \\
\stackrel{\vec{E}}{3} \\
0\end{array}$ & 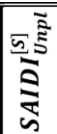 & 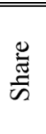 & 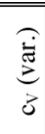 & $\frac{\sqrt[5]{5}}{\bar{\sigma}}$ & $\begin{array}{l}\frac{5}{5} \\
\sum_{z}^{5} \\
\frac{w}{\gamma}\end{array}$ & 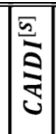 & $\bar{\Xi} \cong$ & $\begin{array}{l}\text { 壳 } \\
\text { 号 }\end{array}$ & $\underbrace{\stackrel{J}{Z}}_{3}$ & 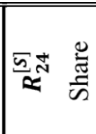 & \\
\hline & $\overline{8}$ & $*$ & $\overline{8}$ & 59 & * & $\overline{89}$ & $\overline{80}$ & * & * & * & $=$ & $\overline{\overline{9}}$ & $\overline{8}$ & $\overline{8}$ & \\
\hline All & $1 \overline{100}$ & 0.4 & 100 & 2 & 0.2 & 100 & 3 & 0.7 & & & 1.9 & 100 & 8 & 0.5100 & \\
\hline 1 & 99.2 & 0.3 & 84 & 2 & 0.2 & 78 & 3 & & & is & .9 & 46 & 0.1 & 0.491 & \\
\hline 2 & 0 & & 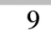 & 13 & 3.3 & 10 & 15 & & & & & 0 & 0.7 & 0.8 & \\
\hline 3 & 0. & & 0 & 45 & 1.5 & 1 & 45 & 3 & & & .0 & & 10.0 & 0.0 & \\
\hline & 0.0 & 103 & 7 & 24 & 103 & 11 & 24 & 50 & 0.0 & 2 & 4200 & 54 & 0.4 & 159 & \\
\hline
\end{tabular}

With respect to the vulnerability analysis results of different months (see Section IV-C), preventive maintenance should be performed during spring (see Fig. 7); vacations should be concentrated in late summer; increased manning, i.e., more human resources, should be considered October-January. This gives a more balanced level of resource utilization throughout the year and also decreased the risk level in general.
TABLE XVIII

DS2-VULNERABILITY WITH RESPECT TO RISK CATEGORIES

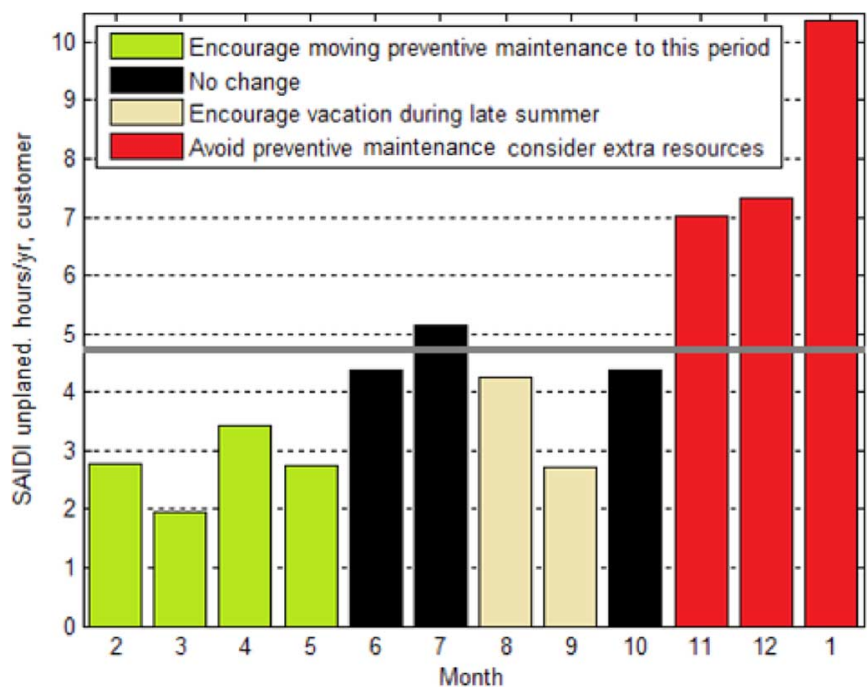

Fig. 7. DS2: example of how results from the proposed vulnerability method could be used in practice.

\section{CONCLUSION}

This paper proposes and demonstrates a vulnerability analysis method to use as decision support for DSOs and also introduce a new reliability index category, $R_{T}$, flexibility to adjust to different laws or DSO policies of long outages. The vulnerability analysis method can be used to allocate resources more cost-effectively, increasing the reliability in general, and decreasing the risk of severe events. The results from an extensive application study, evaluating the method, have been presented. Heavy snowfall and strong winds have great impact on the reliability, while the impact of temperature, rain, snow depth, and power demand are relatively small.

\section{APPENDIX}

The content of Tables II-VII and IX-XVIII is obtained by calculations described in Section III, using empirical data from DS1 and DS2 presented in Section IV-A. According to current Swedish legalization, SAIDI, $\mathrm{R}_{12}$, and $\mathrm{R}_{24}$ are the most important indices to consider.

Additional explanations to Table II-VII and IX-XVIII: 
1st col. List of analyzed states [S], e.g., month or wind speed.

$\mathrm{P}([\mathrm{S}]) \quad$ Probability of being in state $[\mathrm{S}]$. E.g.: "Sunday" $=1 / 7$ and ">30 cm snow (DS2)" $=4.6 \%$ (based on used weather data of 8 year)

Share How many percentage each system state [S] contributes to the actual reliability index.

$\mathrm{C}_{\mathrm{V}}$ (Var.) Coefficient of variation, which indicates the statistical validity (see Section III-F). For example: If $R_{12}^{[S]}$ is equal 40 and is calculated based on 25 events during studied period, then $\mathrm{C}_{\mathrm{V}}=(100) /(\sqrt{25})=20 \%$. This means that $R_{12}^{[S]}$, with a $95 \%$ confidence interval, can be calculated as $40 \pm 1.96 * 0.2 * 40 \approx 40 \pm 15$.

$*$

The units of the reliability indices in this section are as follows: $\mathrm{SAIDI}_{\text {all or unpl }}^{[S]}$ [hours/year, customer], $\mathrm{SAIFI}^{[S]}$ [number of outages (0.05-12 $\mathrm{h}$ long)/year, customer], $\mathrm{AENS}^{[S]}$ [kWh/year, customer], $\mathrm{CAIDI}^{[S]}$ [hours/outage], $R_{T}^{[S]}$ [number of outages ( $>\mathrm{T}$ hours long)/year, customer].

\section{ACKNOWLEDGMENT}

The authors would like to thank O. Hansson, P. Bengtsson and J.-O. Olsson at Fortum Distribution; L. Sandström at Gävle Energi; H. Bobadilla-Robles at The Energy Markets Inspectorate; and M. Tapper at Swedenergy for their contribution of knowledge and input data.

\section{REFERENCES}

[1] C. J. Wallnerström, L. Bertling, and L. A. Tuan, "Risk and reliability assessment for electrical distribution systems and impacts of regulations with examples from Sweden," Int. J. Syst. Assurance Eng. Manage., to be published.

[2] J. D. Andrews and T. R. Moss, Reliability and Risk Assessment, 2nd ed. New York: ASME, 2002.

[3] System and Software Engineering_Life Cycle Processes-Risk Management, ISO/IEC 16085:2006(E), IEEE Std. 16085-2006, 2006, 2nd ed.

[4] K. Wilson et al., "A vulnerability analysis of temperature forests of south central chile," ELSAVIER Biol. Conserv., vol. 122, pp. 9-21, 2005.

[5] C. Ten, C. Lui, and G. Manimaran, "Vulnerability assessment of cybersecurity for SCADA systems," IEEE Trans. Power Syst., vol. 23, no. 4, pp. 1836-1846, Nov. 2008.

[6] E. Jenelius, T. Petersen, and L. Mattson, "Importance and exposure in road network vulnerability analysis," ELSAVIER Transp. Res., vol. 40, pp. 537-560, 2006, Part A.

[7] G. Doorman, K. Uhlen, G. Kjølle, and E. Huse, "Vulnerability analysis of the Nordic power system," IEEE Trans. Power Syst., vol. 21, no. 1, pp. 402-410, Feb. 2006.

[8] P. Wang and R. Billinton, "Reliability cost/worth assessment of distribution systems incorporating time-varying weather conditions and restoration resources," IEEE Trans. Power Del., vol. 17, no. 1, pp. 260-265, Jan. 2002
[9] L. Bertling, R. Allan, and R. Eriksson, "A reliability-centered asset maintenance method for assessing the impact of maintenance in power distribution systems," IEEE Trans. Power Syst., vol. 20, no. 1, pp. 72-82, Feb. 2005.

[10] M. Bollen, "Effects of adverse weather and aging on power system reliability," IEEE Trans. Ind. Appl., vol. 37, no. 2, pp. 252-457, Mar./ Apr. 2001.

[11] R. Billinton and G. Singh, "Application of adverse and extreme adverse weather: Modelling in transmission and distribution system reliability evaluation," Proc. Inst. Elect. Eng., Gen., Transm., Distrib., vol. 153, no. 1, pp. 115-120, Jan. 2006.

[12] Y. Zhou, A. Pahwa, and S. Yang, "Modeling weather-related failures of overhead distribution lines," IEEE Trans. Power Syst., vol. 21, no. 4, pp. 1683-1690, Nov. 2006.

[13] X. Yu and C. Singh, "A practical approach for integrated power system vulnerability analysis with protection failures," IEEE Trans. Power Syst., vol. 19, no. 4, pp. 1811-11820, Nov. 2004.

[14] D. Reed, "Electric utility distribution analysis for extreme winds," $J$. Wind Eng. Ind. Aerodynam., pp. 123-140, 2008.

[15] R. Billinton and Z. Pan, "Historic performance-based distribution system risk assessment," IEEE Trans. Power Syst., vol. 19, no. 4, pp. 1759-1765, Oct. 2004.

[16] C. J. Wallnerström and L. Bertling, "Investigation of the robustness of the Swedish network performance assessment model," IEEE Trans. Power Syst., vol. 23, no. 2, pp. 773-780, May 2008.

[17] J. Setréus, C. J. Wallnerström, and L. Bertling, “A comparative study of regulation policies for interruption of supply of electrical distribution systems in Sweden and UK," in Proc. 19th Int. Conf. Electricity Distribution (CIRED), Vienna, Austria, May 21-24, 2007.

[18] R. Billinton and R. Allan, Reliability Evaluation of Power Systems, 2nd ed. New York: Plenum, 1996.

[19] T. Fan, "Capacity demand and climate in Ekerö-Development of tool to predict capacity demand under uncertainty of climate effects," M.Sc. thesis, School of Elect. Eng., KTH, Stockholm, Sweden, 2007.

[20] P. Hilber, L. Bertling, and B. Hällgren, "Effects of correlation between failures and power consumption on customer interruption cost," in Proc. 9th Int. Conf. Probabilistic Methods Applied to Power Systems (PMAPS), Stockholm, Sweden, 2006.

[21] S. Cullen, "Trees and wind: Wind scales and speeds," J. Arboriculture, vol. 28, no. 5, pp. 237-242, Sep. 2002.

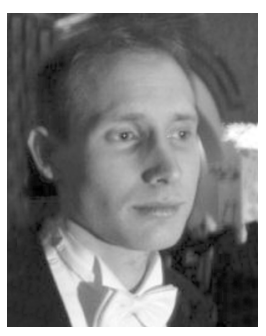

Carl Johan Wallnerström (GS'06) was born in Stockholm in December 1980. He received the M.Sc. degree in electrical engineering and the Licentiate of Engineering degree in electric power systems from KTH - the Royal Institute of Technology, Stockholm, Sweden, in 2005 and 2008, respectively. $\mathrm{He}$ is currently pursuing the Ph.D. degree.

He has been working at KTH School of Electrical Engineering since 2005, first as a research engineer, and from 2006 as a Ph.D. student with the research group RCAM. The title of his Ph.D. project is "Risks related to the introduction of reliability-centered asset management (RCAM) for electrical distribution systems and the effect of regulatory models" and will defend his dissertation entitled "On incentives affecting risk and asset management of power distribution” in September 2011.

Patrik Hilber (GS'02-M'08) was born in Stockholm, Sweden, in 1975. He received the M.Sc. degree in systems engineering and the Tech. Lic. and Ph.D. degrees in electric power systems from KTH-the Royal Institute of Technology, Stockholm, in 2000, 2005, and 2008, respectively.

$\mathrm{He}$ is currently an Assistant Professor at the School of Electrical Engineering, KTH, and since 2008 has been Research Leader for the RCAM research group and manager of the Maintenance Management research program at the Swedish Centre of Excellence in Electric Power Engineering. Recently, he was appointed project manager for two projects on Smart Grids within KIC InnoEnergy. His research interests include maintenance optimization, reliability modeling of power systems, and probabilistic models for age and maintenance. 